\title{
OUT-OF-PLANE BEHAVIOUR OF TUFF AND BRICK MASONRY WALLS STRENGTHENED WITH FRCM COMPOSITE MATERIALS
}

\author{
A. BELLINI ${ }^{*}$, A. INCERTI ${ }^{1}$, A. NANNI ${ }^{2}$ AND C. MAZZOTTI $^{3}$ \\ ${ }^{1}$ CIRI Buildings and Construction (CIRI-EC) \\ University of Bologna \\ Via del Lazzaretto 15/5, 40131 Bologna, Italy \\ e-mail: alessandro.bellini5@unibo.it (*corresponding author), andrea.incerti3@unibo.it \\ ${ }^{2}$ Department of Civil, Architectural and Environmental Engineering \\ University of Miami \\ 1251 Memorial Drive, McArthur Engineering Building, Rm. 325, Coral Gables, FL 33146-0630 \\ e-mail: nanni@miami.edu \\ ${ }^{3}$ Department of Civil, Chemical, Environmental and Materials Engineering (DICAM) \\ University of Bologna \\ Viale Risorgimento 2, 40136 Bologna, Italy \\ e-mail: claudio.mazzotti@unibo.it
}

Keywords: Out-of-plane, Masonry, Brick, Tuff, FRCM, Strengthening

\begin{abstract}
Strengthening with composite materials is becoming more and more an effective solution for increasing the structural safety of masonry buildings, often subjected to severe degradation or potentially vulnerable to seismic events. Structural retrofitting can be performed according to different techniques, based on Fiber Reinforced Polymer (FRP) or Fiber Reinforced Cementitious Matrix (FRCM) strengthening systems. The second group of composite systems is usually preferred nowadays thanks to some important advantages such as better compatibility with the substrate, applicability on wet surfaces, fire resistance, permeability and reversibility. Several experimental and numerical studies can be found in literature concerning masonry panels strengthened with FRP and FRCM systems. The knowledge about the use of the latter, nevertheless, is still partially limited, in particular if the out-of-plane behaviour of walls is taken into account, with the experimental and numerical database available resulting mainly restricted to monotonic cases. In this framework, results of an experimental campaign devoted to the study of the out-of-plane behaviour of tuff and brick masonry walls strengthened with different types of FRCM systems will be presented and discussed in this paper, performing also a comparison with available predictive formulas. Experimental results showed, in general, good performance of FRCM composite materials, with a proper exploitation of their tensile capacity, proving their effectiveness for the out-ofplane strengthening of historical masonry walls.
\end{abstract}




\section{INTRODUCTION}

Historical buildings and civil constructions are commonly made, especially in the Southern Europe area, with stone, brick or tuff elements coupled with hydraulic lime-based mortars, for realizing different types of masonries. The masonry panels behaviour, primarily as a reaction to horizontal actions triggered for example during a seismic event, represents a key issue to be investigated, in order to improve structural safety of the constructions, avoiding local and global failure mechanisms.

In the last years, several studies have been carried out on masonry elements retrofitted with composite materials such as Fiber Reinforced Polymers (FRPs) or Fiber Reinforced Cementitious Matrix (FRCM) systems, highlighting advantages and drawbacks of these two kinds of strengthening techniques, starting from applicability on wet surfaces until fire resistance or compatibility and removability of the strengthening materials used [1-12]. However, only few works are focused on the out-of-plane behaviour of masonry walls built with different masonry substrates and strengthened with composite materials [13-17].

In this framework, the objective of the present study is to improve the knowledge about failure modes and performances of two particular masonry substrates (made with tuff stones and clay bricks) when retrofitted with FRCM systems comprising basalt, aramid-glass fiber grids and steel fiber sheets, using also different layouts during their application to masonry panels. A specific, purposely made experimental set-up, validated during previous laboratory flexural tests $[15,16]$, was used to simulate the effect of a distributed out-of-plane load, such

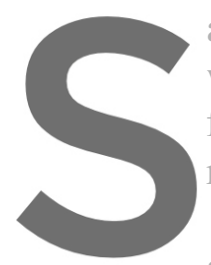
as that generated during a seismic event and
were then discussed in terms of maximum be
failure, highlighting the effects of the FRC
reference unreinforced panel.
Finally, predictive formulas, expressed in approach [18], were compared with the experim
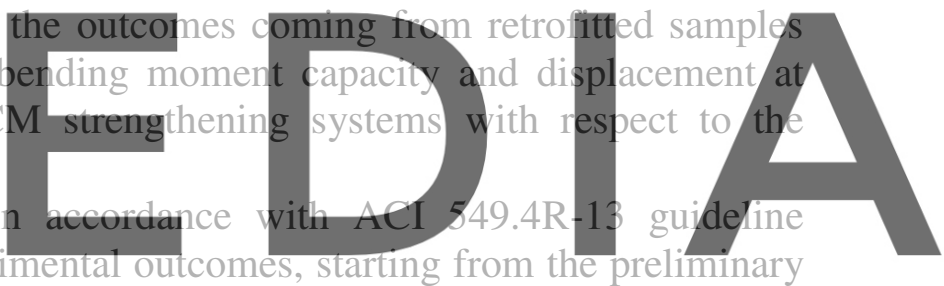
mechanical characterization of the materials used for retrofitting the masonry walls.

Register for free at https//www.scipedia.com to download the version without the watermark 2 MATERIALS AND SAMPLES PREPARATION

The experimental campaign carried out for the evaluation of the out-of-plane behaviour of tuff and brick masonry walls strengthened with FRCM composites is summarized in Table 1, where each specimen type is identified with a simple code containing the wall substrate $(\mathrm{B}=$ brick or $\mathrm{T}=$ tuff masonry), the applied FRCM system (basalt G2, aramid-glass R1, steel G6 or steel G12) and the number of FRCM plies. For each sample type, a single test repetition was performed, for a total number of 12 out-of-plane flexural tests.

Details and mechanical characterization of masonry walls and FRCM strengthening systems will be discussed in the following.

\subsection{Masonry walls}

The masonry walls tested were built with both clay bricks and tuff blocks using the same low strength natural hydraulic lime (NHL) mortar for bed joints. Clay brick masonry samples were double-leaf panels with dimensions of $1.20 \times 0.25 \times 2.70 \mathrm{~m}^{3}$, fabricated from standard clay bricks with nominal size $250 \times 120 \times 55 \mathrm{~mm}^{3}$, adopting a mortar joints thickness of about 10 mm. Tuff block masonry instead was built starting from tuff blocks with nominal size 
$370 \times 245 \times 105 \mathrm{~mm}^{3}$, resulting in a masonry panel with total dimensions of $1.13 \times 0.245 \times 2.70$ $\mathrm{m}^{3}$. The samples were cured in laboratory-controlled conditions after construction and before the application of FRCM strengthening systems. Materials characterization was carried out by testing masonry prisms [19] and mortar cubes [20] in compression after 28 days of curing. The obtained average compressive strength of masonry prisms was $8.50 \mathrm{MPa}$ and $2.08 \mathrm{MPa}$, respectively, for clay brick and tuff masonry, whereas the mean 28 days mortar cubes compressive strength was $2.52 \mathrm{MPa}$.

Table 1: Experimental campaign.

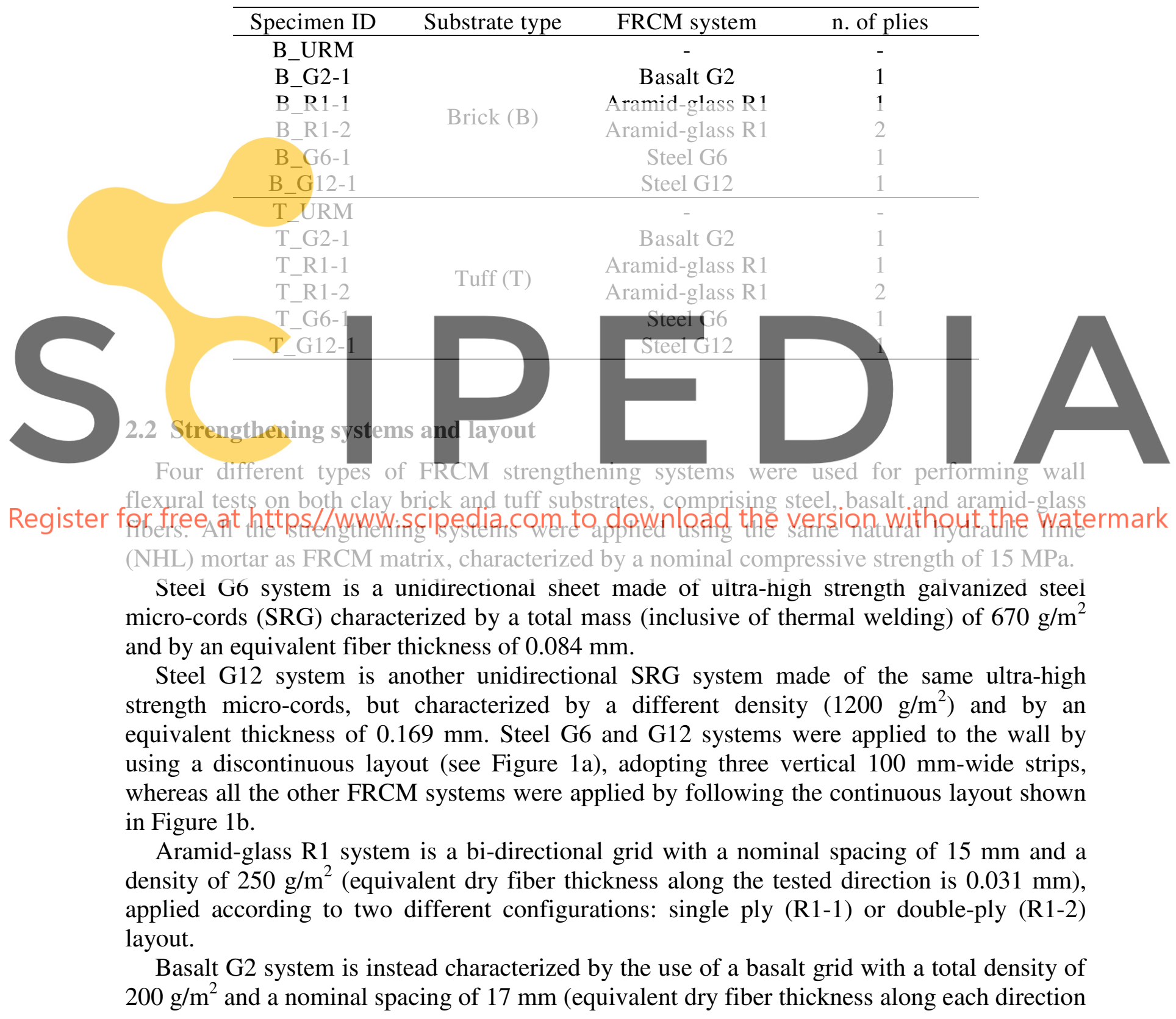


is $0.032 \mathrm{~mm}$ ). All the FRCM/SRG systems were mechanically characterized at University of Miami according to AC 434 Annex A [21], performing tensile tests in order to evaluate the ultimate tensile strength, the cracked and uncracked moduli of elasticity and the ultimate tensile strain of the strengthening systems. The obtained average values, which will be used for comparison between experimental results coming from wall flexural tests and predictive formulas [18], are summarized in Table 2.
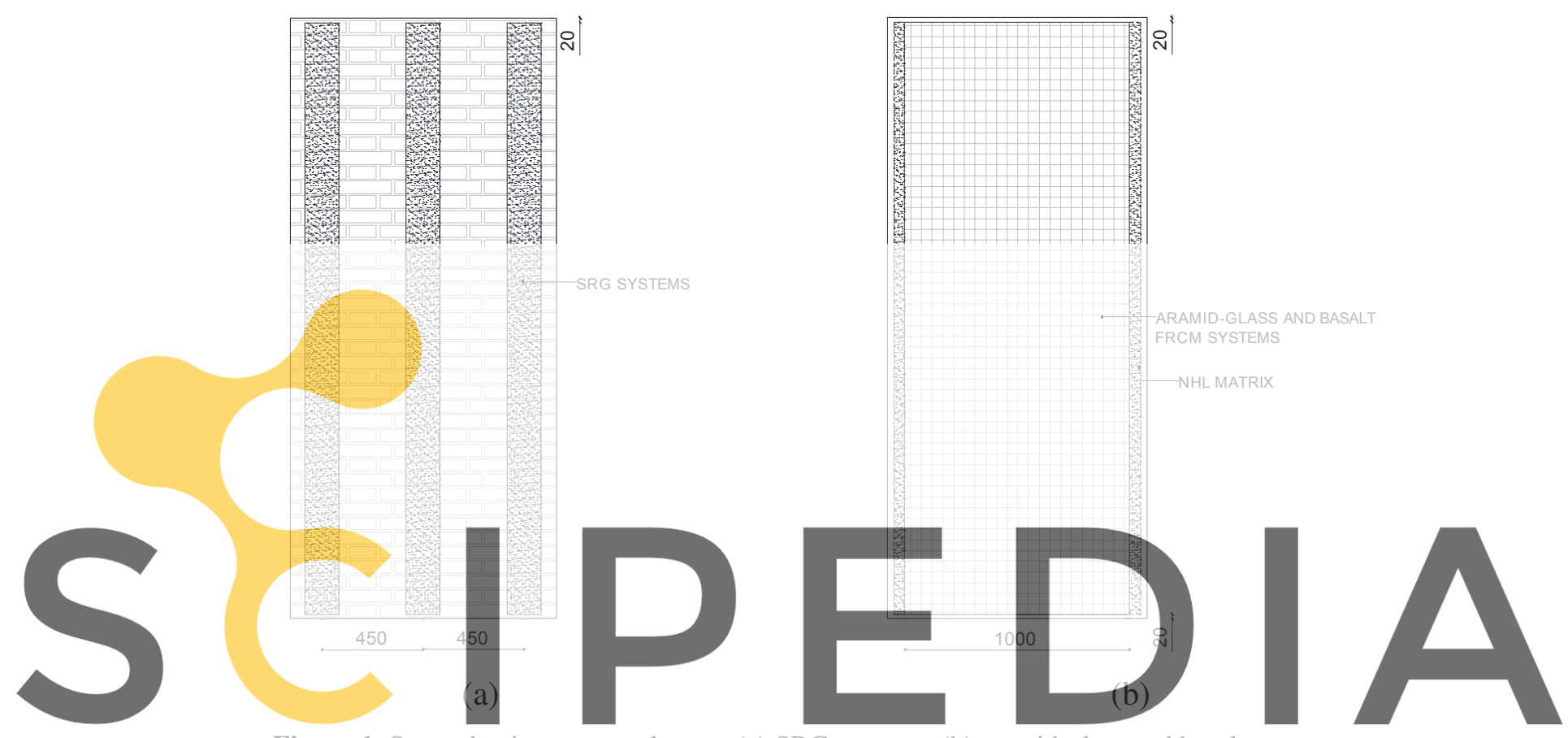

Figure 1: Strengthening systems layout: (a) SRG systems; (b) aramid-glass and basalt systems.

Register for free at https//www.scipedia.com to download the version without the watermark Table 2: Materials characterization: results of tensile tests on FRCM systems according to AC434, Annex A.

\begin{tabular}{|c|c|c|c|c|}
\hline $\begin{array}{c}\text { Strengthening } \\
\text { system }\end{array}$ & $\begin{array}{c}\text { Ultimate stress } \\
\text { [MPa] }\end{array}$ & $\begin{array}{c}\text { Cracked modulus } \\
\text { of elasticity } \\
\text { [GPa] }\end{array}$ & $\begin{array}{c}\text { Uncracked modulus } \\
\text { of elasticity } \\
\text { [GPa] }\end{array}$ & $\begin{array}{c}\text { Ultimate strain } \\
{[\%]}\end{array}$ \\
\hline G6 & 884.1 & 58.51 & 452.9 & 1.42 \\
\hline G12 & 617.5 & 37.27 & 400.9 & 1.08 \\
\hline R1 & 1188.0 & 30.63 & 2054.5 & 2.93 \\
\hline $\mathrm{G} 2$ & 685.2 & 46.65 & 1784.5 & 1.86 \\
\hline
\end{tabular}

\section{OUT-OF PLANE TEST SET-UP}

The experimental set-up used for evaluating the flexural capacity of clay brick and tuff masonry walls was a purposely designed set-up, able to test full-scale samples, previously validated during several experimental campaigns carried out on FRCM-strengthened masonry panels $[15,16]$.

The set-up, shown in Figure 2, allowed to place the walls following a simply supported 
static scheme, adopted to induce flexural failure, and to apply horizontal loads together with a constant uniform vertical compression axial stress ( $\sigma=0.2 \mathrm{MPa}$ for clay brick masonry walls and $\sigma=0.15 \mathrm{MPa}$ for tuff samples). Out-of-plane forces were applied along four symmetrically distributed positions, generating a bending moment distribution quite similar to that produced by a uniform distributed load. Test walls were anchored to the reaction wall and to the laboratory strong floor by means of steel elements, allowing the panels to bend in the out-of-plane direction.

Pressure transducers were used to measure independently the out-of-plane forces and the vertical stress, applied by using two independent hydraulic circuits. Horizontal displacements at the top, bottom and mid-height of the walls were measured by means of draw-wire displacement transducers (WDTs). Two additional displacement transducers (LVDTs) were used to measure rotation of the bottom hinge.

Further details on the adopted experimental set-up can be found in [15].

Tests were performed under horizontal force control at a rate equal to $2 \mathrm{kN} /$ minute, adopting a data acquisition rate of $2 \mathrm{~Hz}$.
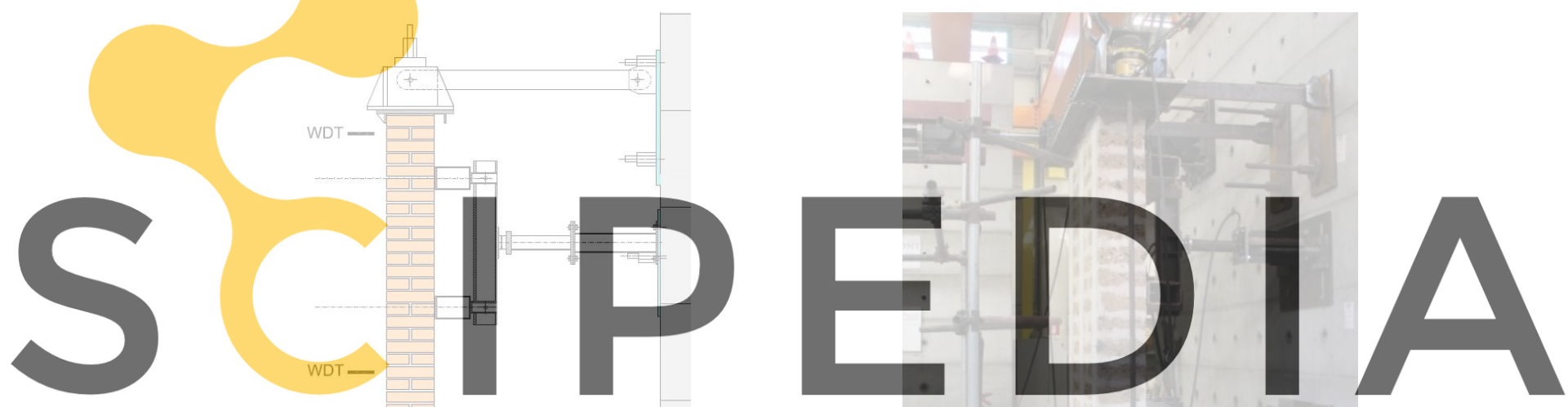

Register for free at https//www.scjpedia.com to download the version without the watermark
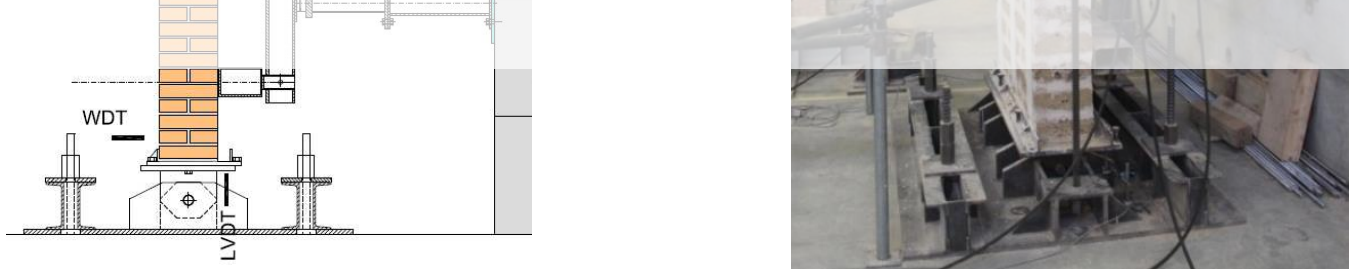

Figure 2: Experimental set-up.

\section{EXPERIMENTAL RESULTS}

Experimental results in terms of failure modes, maximum capacity and moment-deflection curves will be presented and discussed in this section.

\subsection{Failure modes}

Table 3 and Table 4 show the results obtained for both clay brick and tuff brick walls. The two different failure modes identified during out-of-plane tests are shown in Figure 3: 
a) flexural failure with fiber tensile rupture (Figure 3a) or $b$ ) shear failure of the strengthened wall (Figure $3 b$ ). In more detail, flexural failure always occurred due to the tensile failure of the FRCM fabric in proximity of the panel mid-height, in a portion of the wall where the bending moment was constant and maximum, and it was always located in correspondence of a previously cracked section of the masonry wall. Shear failure were observed from walls strengthened by high density steel fabric (B_G12-1, T_G12-1) or with low substrate mechanical properties (T_G6-1).

Table 3: Out-of-plane test results: clay brick substrate specimens.

\begin{tabular}{ccccc}
\hline Specimen & Failure mode & $\begin{array}{r}\text { Maximum capacity } \\
\mathbf{M}_{\max } \\
{[\mathrm{kN} \mathrm{m}]}\end{array}$ & $\begin{array}{c}\text { Increment } \\
{[\%]}\end{array}$ & $\begin{array}{c}\text { Maximum deflection } \\
\boldsymbol{\delta}_{\max } \\
{[\mathrm{mm}]}\end{array}$ \\
\hline B_URM & Flexure & 9.80 & - & 6.66 \\
B_G2-1 & Flexure & 14.56 & +48.57 & 12.08 \\
B_R1-1 & Flexure & 22.99 & +134.59 & 44.94 \\
B_R1-2 & Flexure & 31.76 & +224.08 & 47.00 \\
B_G6-1 & Flexure & 32.35 & +230.10 & 63.92 \\
B_G12-1 & Shear & 30.69 & +213.16 & 34.07 \\
\hline
\end{tabular}

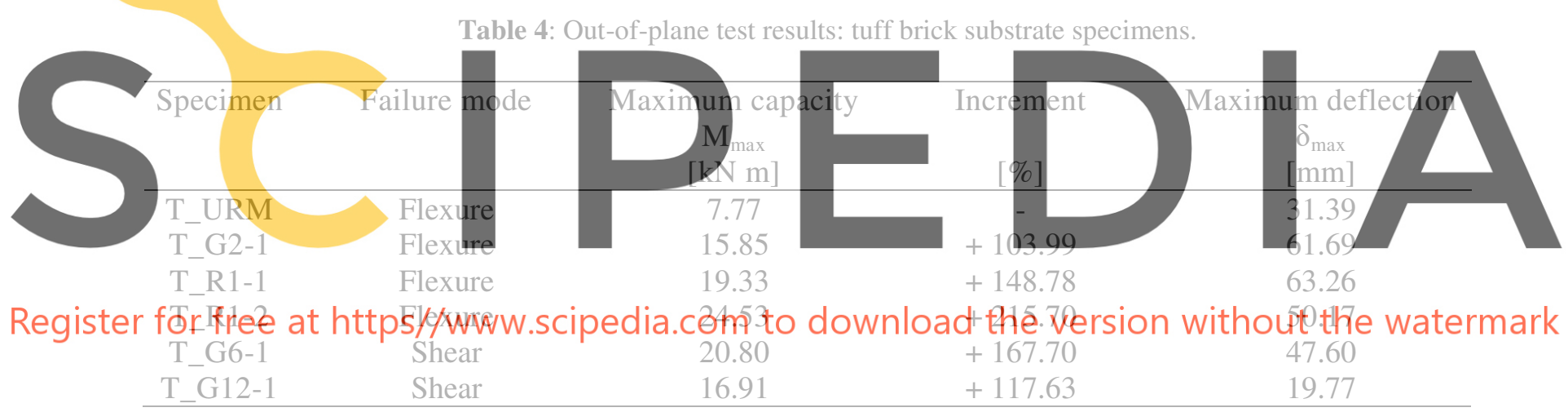

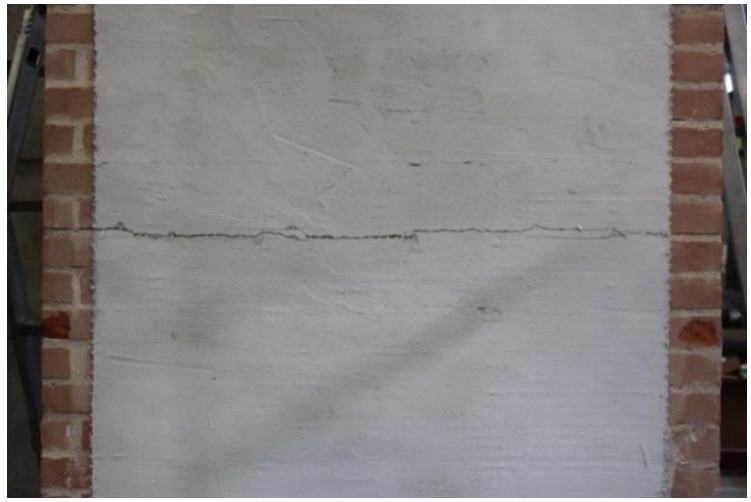

(a)

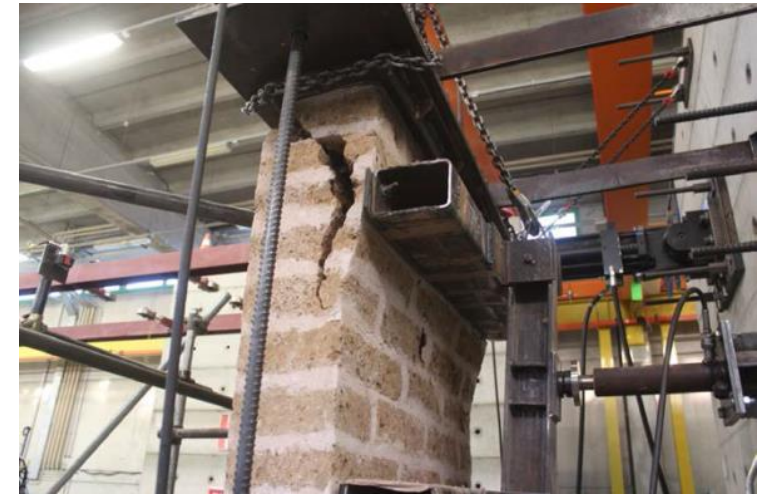

(b)

Figure 3: Test results: typical failure modes: (a) flexural failure with fiber tensile rupture; (b) shear failure. 


\subsection{Out-of-plane capacity and moment-deflection curves}

The maximum bending moment $M_{\max }$ reached during the out-of-plane experimental tests, in comparison to the unreinforced masonry (URM) walls is indicated in Table 3 and Table 4, respectively, for clay brick and tuff walls, together with the maximum deflection $\delta_{\max }$.

Steel (G6 and G12) and aramid-glass (R1) strengthening systems showed the best results, with an optimal efficiency moving from one ply (R1-1) to two plies (R1-2) in the case of aramid-glass samples. All the samples, except for B_G12-1 wall, proved to be able to reach the maximum strengthening system capacity without premature debonding phenomena or shear failure of the substrate. The capacity increment, in comparison to the unreinforced sample, was remarkable for all the brick walls tested, ranging from a minimum of $48 \%$ to a maximum of $230 \%$.

The same comparison made for tuff masonry walls highlighted some differences: the premature shear failure of the substrate limited the maximum capacity of SRG strengthened samples, whereas G2 and R1 bidirectional grids reached their mechanical capacity. As for brick samples, a good increment was found passing from one ply to two plies in the case of R1 strengthening system. The difference between strengthened and URM walls was included in the $104-216 \%$ range, highlighting again the good efficiency of FRCM strengthening systems also in case of substrates with lower mechanical properties.

Figure 4 shows the moment-deflection curves obtained during flexural tests for all the walls tested, including clay brick (Figure 4a) and tuff substrate (Figure 4b). As a general

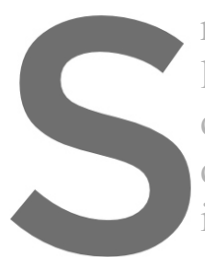
remark, all the strengthened samples showed a typical biline linear phase until the ons characterized by a progressively decreasing constant positive slope. The curves, in general in terms of maximuin evident increment in displacement capacity (see Figure 4 and Tables 3,4).

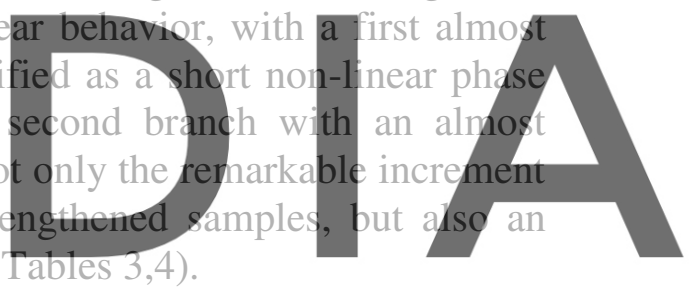

Register for ${ }_{3}$ free at https//www.scipedia.com to download the version without the watermark

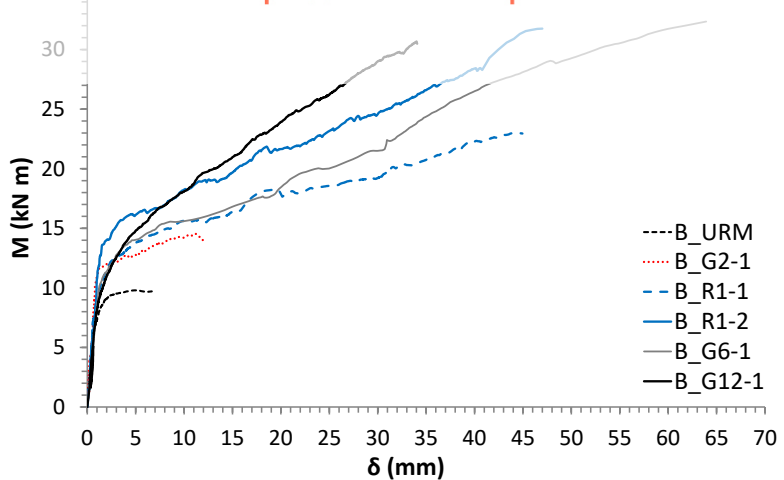

(a)

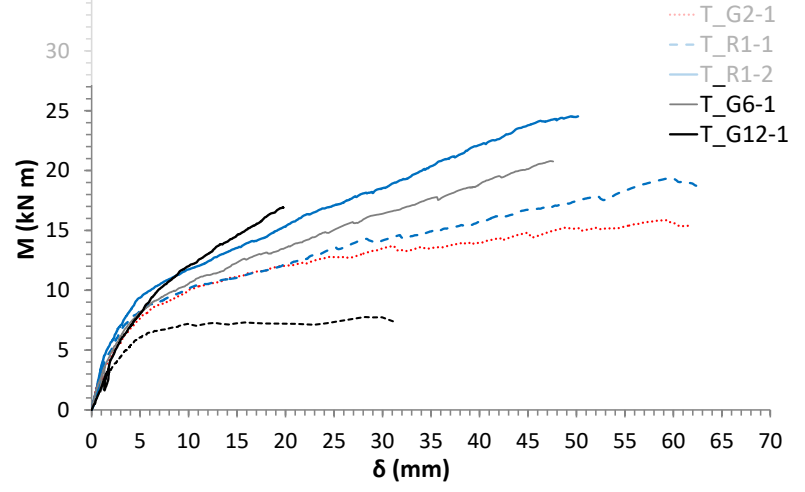

(b)

Figure 4: Out-of-plane test results: moment-deflection curves: (a) clay brick walls; (b) tuff masonry walls. 


\subsection{Discussion of experimental results: comparison between brick and tuff masonry}

If moment-deflection curves obtained from the two different substrates are compared, considering the same strengthening system type, some general trends can be observed (see Figure 5). First of all, since the out-of-plane capacity depends both on masonry mechanical properties and on the strengthening system efficiency, retrofitted clay brick walls showed, as expected, higher out-of-plane flexural capacity if compared to strengthened tuff masonry walls. If initial stiffness of moment-deflection curves is analyzed, again tuff masonry, characterized by weaker mechanical properties, showed the worst results, independently from the FRCM system type considered. Analyzing maximum displacement capacity of basalt and aramid-glass FRCM systems (Figure 5a), the maximum deflection registered during experimental tests was generally similar or higher for tuff masonry walls. When dealing with G6 and G12 steel systems instead (see Figure 5b), the premature shear failure of masonry substrate caused a completely different trend, with a reduced displacement capacity for tuff samples when compared with similarly strengthened clay-brick walls.

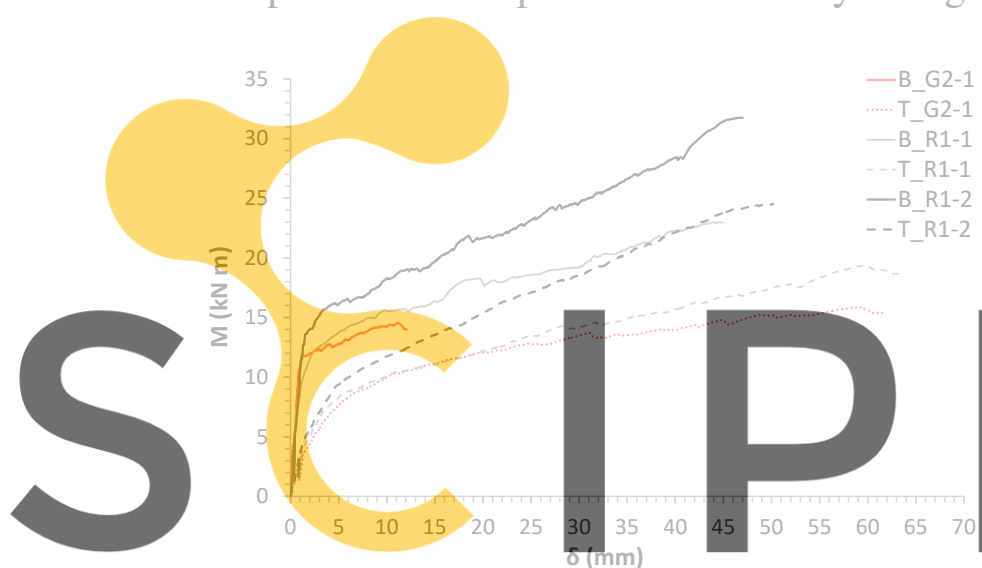

(a)

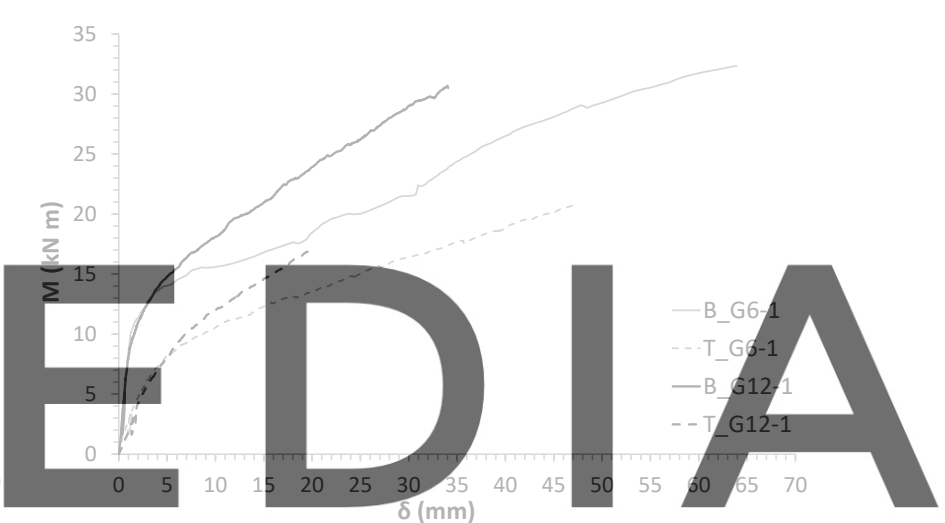

(b)

Register for free at https/fwww. scipediaccom to d owndoad the version without the watermark R1 systems; (b) G6 and G12 steel systems.

\section{COMPARISON WITH PREDICTIVE FORMULAS}

Out-of-plane flexural capacity $M_{n}$ of masonry walls has been also estimated by following the ACI 549.4R-13 approach [18], starting from the definition of the effective tensile strain and stress levels of the composite at failure. Results have been then compared with experimental findings $M_{\max }$.

The effective tensile strain of the FRCM composite material can be evaluated from tensile tests performed according to AC 434 Annex A (Table 2). Since the purpose of the comparison is not to calculate design values, but to compare predictive formulas with experimental results, ultimate strain values reported in Table 2 will be considered as effective tensile strain values $\varepsilon_{f e}$, without the strain limitation $\varepsilon_{f e} \leq 0.012$ contained inside ACI 549.4R13 [18], suitable for design of the strengthened elements.

Following this approach, the effective tensile stress level at failure $f_{f e}$ is:

$$
f_{f e}=E_{f} \cdot \varepsilon_{f e}
$$


where $E_{f}$ is the tensile modulus of elasticity of the cracked FRCM composite material (see Table 2) and considering the stress limitation $f_{f e} \leq f_{f u}$, where $f_{f u}$ identifies the experimental ultimate tensile strength of the FRCM composite.

Starting from the effective tensile stress at failure and assuming the stress block factors $\beta_{1}=0.7$ and $\gamma=0.7$, respectively for the extension of the part under compression and the intensity of the uniform stress, equilibrium of forces can be used to calculate the neutral axis depth $c$. If the failure mode is governed by FRCM failure:

$$
c=\frac{Q+n_{f} \cdot A_{f} \cdot f_{f e}}{\gamma \cdot f_{m}^{\prime} \cdot \beta_{l} \cdot B}
$$

where $Q$ is the applied axial force, $n_{f}$ the number of plies of the FRCM system, $A_{f}$ the FRCM composite area per ply, $f^{\prime}{ }_{m}$ the compressive strength of masonry and $B$ the width of the masonry wall. After calculating the neutral axis depth, and indicating with $t_{w}$ the wall thickness, the nominal flexural strength $M_{n}$ can be determined as:

$$
M_{n}=\gamma \cdot f_{m}^{\prime} \cdot \beta_{l} \cdot c \cdot B \cdot\left(\frac{t_{w}}{2}-\beta_{l} \cdot \frac{c}{2}\right)+n_{f} \cdot A_{f} \cdot f_{f e} \cdot \frac{t_{w}}{2}
$$

It should then be verified that the compressive strain in the masonry does not exceed the ultimate value $\varepsilon_{m u}$, generally assumed equal to 0.0035 :
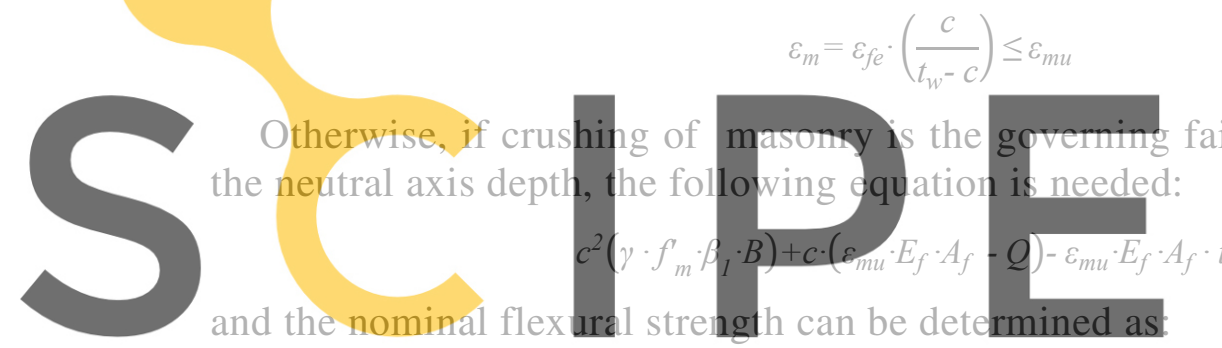

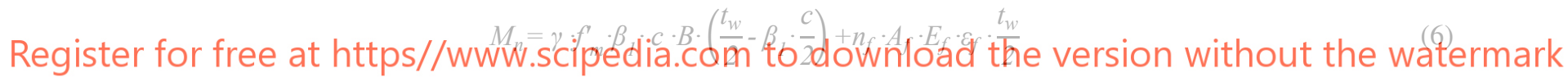

Finally, if this second failure mode occurs, it should be verified that the tensile strain in

the fiber does not exceed the uitimate strain value $\varepsilon_{f u}$, determined through mechanical characterization of the FRCM material (see Table 2):

$$
\varepsilon_{f}=\varepsilon_{m u} \cdot\left(\frac{t_{w} c}{c}\right) \leq \varepsilon_{f u}
$$

The out-of-plane nominal capacity $M_{n}$, calculated according to this theoretical formulation, is reported in Table 5 and Table 6 , respectively, for clay brick and tuff masonry walls and compared with the experimental capacity $M_{\max }$.

As can be observed from the tables, ACI $549.4 \mathrm{R}-13$ approach provides results that are on the safe side, with ratio $M_{\max } / M_{n}$ ranging from 1.26 to 2.79 for clay brick masonry panels and from 1.88 to 2.75 for strengthened tuff masonry walls. Figure 6a, where experimental and theoretical values of each clay brick masonry specimen are compared, shows, in more detail, a good approximation for G2 basalt samples, but a completely different result, with a larger underestimation of experimental outcomes, in the case of steel and aramid-glass samples with 2 plies. The same trend can be also observed for tuff walls strengthened with basalt and aramid-glass FRCMs (Figure 6b), but cannot be 
confirmed for those retrofitted with G6 and G12 steel strengthening systems, where shear failure occurred in masonry before reaching the maximum out-of-plane flexural capacity.

Table 5: Comparison with predictive formulas: clay brick masonry walls.

\begin{tabular}{cccc}
\hline Specimen & $\begin{array}{c}\text { Experimental capacity } \mathbf{M}_{\max } \\
{[\mathrm{kN} \mathrm{m}]}\end{array}$ & $\begin{array}{c}\text { Nominal capacity } \mathrm{M}_{\mathrm{n}} \\
{[\mathrm{kN} \mathrm{m}]}\end{array}$ & $\begin{array}{c}\mathrm{M}_{\max } / \mathrm{M}_{\mathrm{n}} \\
{[]}\end{array}$ \\
\hline B_URM & 9.80 & 7.25 & 1.35 \\
B_G2-1 & 14.56 & 11.55 & 1.26 \\
B_R1-1 & 22.99 & 9.99 & 2.30 \\
B_R1-2 & 31.76 & 12.72 & 2.50 \\
B_G6-1 & 32.35 & 11.61 & 2.79 \\
B_G12-1 & 30.69 & 12.24 & 2.51 \\
\hline
\end{tabular}

Table 6: Comparison with predictive formulas: tuff masonry walls.

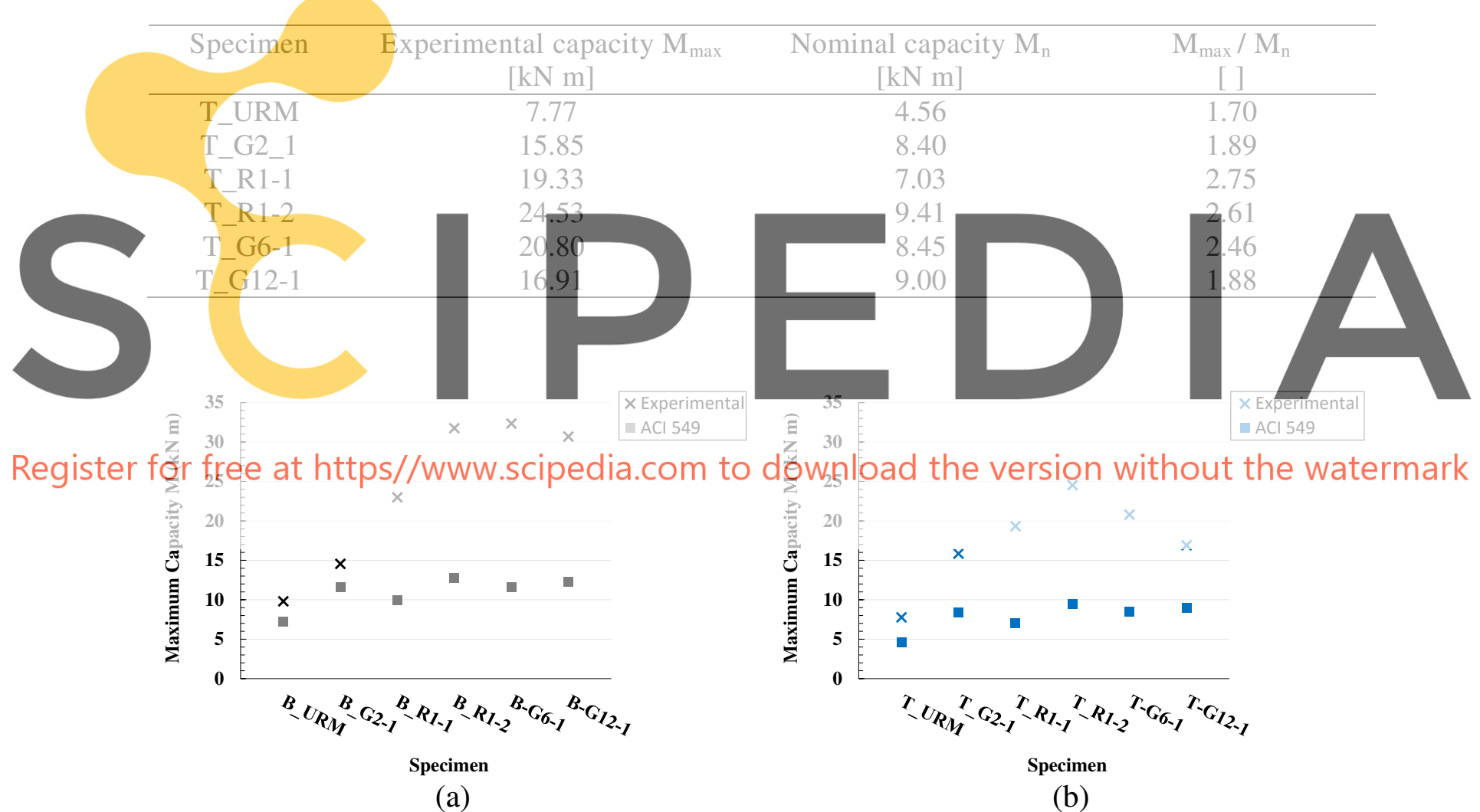

Figure 6: Comparison between experimental results and predictive formulas (ACI 549.4R-13): (a) clay brick masonry walls; (b) tuff masonry walls.

\section{CONCLUSIONS}

The paper presents the results of an experimental campaign focused on the evaluation of the out-of-plane behaviour of clay brick and tuff masonry walls retrofitted with FRCM composite materials. 
Flexural tests were performed by using a purposely design set-up, able to independently apply an axial force and out-of-plane horizontal forces on a full-scale masonry panel, evaluating failure modes and capacity of the strengthened walls. The experimental results showed a good efficiency of the strengthening systems, with capacity increments, in comparison to the URM wall, ranging from $48 \%$ to $230 \%$ for brick masonry samples and from $104 \%$ to $216 \%$ for tuff specimens.

The most common failure mode was flexural failure of the wall with final tensile failure of the FRCM reinforcement, with only a few cases of shear failure, involving high density steel strengthening systems.

Tests were also performed on aramid-glass fibers, investigating the effect of a different number of plies and highlighting that a remarkable capacity increment is possible passing from one to two plies, at least for low density fabrics, without changing the failure mode of the strengthened wall.

Finally, starting from mechanical characterization of the FRCM systems, a comparison between experimental capacity and nominal capacity, calculated according to ACI 549.4R-13 [18] approach, was performed, obtaining values of their ratio ranging from 1.26 to 2.79 for clay brick masonry walls and from 1.88 to 2.75 for strengthened tuff specimens and therefore concluding that theoretical values are always on the safe side, with an underestimation of experimental outcomes.

Acknowledgements. The authors would like to thank Kerakoll S.p.A. for providing materials and for strengthening systems application. The financial support of the Italian Department of Civil Protection (ReLUIS 2019-2021 Grant - Innovative Materials) is gratefully acknowledged.

\section{REFERENCES}

[1] Carloni, C., and Subramaniam, K.V. FRP-masonry debonding: numerical and experimental study of the role of mortar joints. J. Compos. Constr. (2012) 16:581-589.

[2] Mazzotti, C., Ferracuti, B., and Bellini, A. Experimental bond tests on masonry panels strengthened by FRP. Composites Part B (2015) 80:223-237.

[3] De Felice, G., De Santis, S., Garmendia, L., Ghiassi, B., Larrinaga P., Lourenço, P.B., Oliveira D.V., Paolacci F. and Papanicolau C.G. Mortar-based systems for externally bonded strengthening of masonry. Materials and Structures (2014) 47:2021-2037.

[4] Carozzi, F.G., Bellini, A., D’Antino, T., de Felice, G., Focacci, F., Hojdys, L., Laghi, L., Lanoye, E., Micelli, F., Panizza, M. and Poggi, C. Experimental investigation of tensile and bond properties of Carbon-FRCM composites for strengthening masonry elements. Composites Part B (2017) 128:100-119.

[5] Papanicolaou, C., Triantafillou, T. and Lekka, M. Externally bonded grid as strengthening and seismic retrofitting materials of masonry panels. Construction and Building Materials (2011) 25(2):504-514.

[6] Bellini, A., Bovo, M. and Mazzotti, C. Experimental and numerical evaluation of fibermatrix interface behaviour of different FRCM systems. Composites Part B (2019) 161:411-426. 
[7] Bellini, A., Shahreza, S.K. and Mazzotti, C. Cyclic bond behavior of FRCM composites applied on masonry substrate. Composites Part B (2019) 169:189-199.

[8] Incerti, A. Tilocca, A.R., Ferretti, F. and Mazzotti, C. Influence of masonry texture on the shear strength of FRCM reinforced panels. In: R. Aguilar et al. (Eds.): Structural Analysis of Historical Constructions, RILEM Bookseries 18 (2019), pp. 1623-1631.

[9] Incerti, A., Ferretti, F. and Mazzotti, C. FRCM strengthening systems efficiency on the shear behavior of pre-damaged masonry panels: an experimental study. J Build Rehabil (2019) 4: 14. DOI: 10.1007/s41024-019-0053-9.

[10] Ferretti, F., Incerti, A., Tilocca A.R. and Mazzotti, C. In-Plane Shear Behavior of Stone Masonry Panels Strengthened through Grout Injection and Fiber Reinforced Cementitious Matrices. International Journal of Architectural Heritage (2019). DOI: 10.1080/15583058.2019.167580.

[11] Sassoni, E., Andreotti, S., Bellini, A., Mazzanti, B., Bignozzi M.C., Mazzotti, C. and Franzoni E. Influence of mechanical properties, anisotropy, surface roughness and porosity of brick on FRP debonding force. Compos Part B (2017) 108:257-269.

[12] Lignola, G.P., Caggegi, C., Ceroni, F., De Santis, S., Krajewski, P., Lourenço, P.B., Morganti, M., Papanicolaou, C., Pellegrino, C., Prota, A., and Zuccarino, L. Performance assessment of Basalt FRCM for retrofit applications on masonry. Compos Part B (2017) 128:1-18.

[13] Babaeidarabad, S., De Caso, F., and Nanni, A. Out-of-plane behavior of URM walls strengthened with Fabric-Reinforced Cementitious Matrix Composite. J Compos Constr 18 (2014). DOI 10.1061/(ASCE)CC.1943-5614.0000457.

[14] Harajli, M., ElKhatib, H., and Tomas San-Jose, J. Static and cyclic out-of-plane response of masonry walls strengthened using textile-mortar system. J Mater Civil Eng (2010) 22: 1171-1180.

[15] Bellini, A., Incerti, A., Bovo, M. and Mazzotti, C. Effectiveness of FRCM reinforcement applied to masonry walls subject to axial force and out-of-plane loads evaluated by experimental and numerical studies. International Journal of Architectural Heritage (2018) 12(3):376-394.

[16] Bellini, A., Incerti, A. and Mazzotti, C. Out-of-plane strengthening of masonry walls with FRCM composite materials. Key Engineering Materials (2017) 747:158-165.

[17] De Santis, S., Bellini, A., de Felice, G., Mazzotti, C., and Meriggi, P. Design of the outof-plane strengthening of masonry walls with textile reinforced mortar composites. 9 th International Conference on Fibre-Reinforced Polymer (FRP) Composites in Civil Engineering - CICE 2018. 17-19 July, Paris, France. 2018.

[18] ACI 549.4R-13. Guide to design and construction of externally bonded FabricReinforced Cementitious Matrix (FRCM) systems for repair and strengthening concrete and masonry structures. 2013.

[19] ASTM C1314-16. Standard Test Method for Compressive Strength of Masonry Prisms. 2016.

[20] ASTM C109/C109M-16a. Standard Test Method for Compressive Strength of Hydraulic Cement Mortars (Using 2-in. or 50-mm Cube Specimens). 2016.

[21] AC 434. Acceptance criteria for masonry and concrete strengthening using Fabric Reinforced Cementitious Matrix (FRCM) and Steel Reinforced Grout (SRG) composite systems. 2016. 